\title{
MODIFIKASI DESIGN HEATSINK DAN DUDUKAN PELTIER PADA ALAT TRANSPORTASI IKAN SEGAR
}

\section{Design Modification of Heatsink and Peltier Base Plate for Refrigerated Fresh Fish Container}

\author{
Tri Nugroho Widianto*, Luthfi Assadad, dan Ahmat Fauzi \\ Loka Riset Mekanisasi Pengolahan Hasil Perikanan, JI. Imogiri Barat KM. 11,5, Yogyakarta, Indonesia \\ *Korespondensi Penulis: trinugrohowidianto@yahoo.com \\ Diterima: 26 Mei 2020; Direvisi: 17 Juli 2020; Disetujui: 7 Agustus 2020
}

\begin{abstract}
ABSTRAK
Alat transportasi ikan segar (ALTIS) adalah sarana pendingin yang dapat mempertahankan mutu ikan segar. ALTIS umumnya digunakan oleh pedagang kelliling dalam transportasi dan distribusi produknya. Komponen yang menentukan kinerja pendingin adalah heatsink dan dudukan peltier. Kedua bagian ini berfungsi dalam transfer panas kotak penyimpanan ikan menuju udara. Namun, biaya produksi dan harga material kedua komponen tersebut cukup tinggi. Penelitian ini bertujuan untuk modifikasi spesifikasi heatsink dan dudukan peltier, agar mendapatkan efisiensi biaya pembuatannya. Heatsink dibuat dari $3 \mathrm{~mm}$ plat tembaga dengan 18 sirip aluminium yang memiliki ketinggian $10 \mathrm{~mm}$ dan ketebalan $1 \mathrm{~mm}$. Sementara itu, dudukan peltier juga dibuat dari alumunium dengan ketebalan bervariasi $(4,5,6$, dan $10 \mathrm{~mm})$. Performa kedua bagian ini diuji dengan variabel suhu heatsink dalam, heatsink luar, dan ruang penyimpanan ikan, setiap 5 menit selama 95 menit. Hasil pengujian menunjukkan bahwa suhu ruang penyimpanan ikan menggunakan heatsink baru $\left(17,8^{\circ} \mathrm{C}\right)$ lebih rendah dari heatsink sebelumnya $\left(18,3^{\circ} \mathrm{C}\right)$. Desain heatsink yang baru ini dapat mengurangi biaya pembuatan sebesar Rp. 807.000,00. Dudukan elemen peltier dengan alumunium setebal $4 \mathrm{~mm}$ dapat mempercepat proses perpindahan panas dari ruang penyimpanan ikan menuju peltier. Modifikasi ini dapat diaplikasikan untuk menurunkan biaya dan meningkatkan performa ALTIS.
\end{abstract}

KATA KUNCI : alat transportasi ikan segar, dudukan peltier, heatsink, peltier, suhu

\section{ABSTRACT}

Refrigerated Fresh Fish Container (ALTIS) is a cooler equipment to maintain the quality of fresh fish. ALTIS is usually used by the itinerant fish traders to preserve their products in transportation and distribution. The components that determine the cooler performance are the heatsinks and the Peltier base plate. These components are responsible for transferring the heat from the fish container to the air. However, the production costs and material price for both components are expensive. This study aimed to reduce production costs by modifying the heatsink and Peltier base plate design specifications. The heatsink was made from $3 \mathrm{~mm}$ thickness copper and aluminum fins. The aluminum fins were 18 pieces in total, with $1.6 \mathrm{~mm}$ thickness and $10 \mathrm{~mm}$ height. Meanwhile, the Peltier base plate was also made from aluminum with varied thicknesses $(4,5,6$, and $10 \mathrm{~mm})$. The performance of both parts was evaluated by temperature measurement in the inner heatsink, outer heatsink, and box container for every 5 minutes in 95 minutes. The results showed that the refrigerated container box temperature with the new heatsink $\left(17.8^{\circ} \mathrm{C}\right)$ was lower than the existing heatsink $\left(18.3^{\circ} \mathrm{C}\right)$. Moreover, the new heatsink design may reduce the production costs by Rp. 807,000.00. Furthermore, the Peltier base plate with a $4 \mathrm{~mm}$ thickness could accelerate the heat-dissipating of Peltier. Thus, the modification can be applied for ALTIS production with lower cost and better performance.

KEYWORDS: fish refrigerated container, heatsink, peltier, peltier base plate, temperature

\section{PENDAHULUAN}

Alat transportasi ikan segar (ALTIS) adalah sarana pedagang ikan keliling untuk membawa dan mendistribusikan produknya. Alat ini dilengkapi dengan pendingin, sehingga mampu mempertahankan mutu ikan segar dan memudahkan penjualannya (Hakim, Siregar, Widianto \& Purnomo, 2016; Widianto, Hermawan \& Utomo, 2014). Penyimpanan ikan pada suhu rendah dapat memperlambat pertumbuhan dan aktivitas mikroba pembusuk, serta reaksi oksidasi dan enzimatik (Gelman, Glatman, 
Drabkin, \& Harpaz, 2001; Kotta, Moeller, Orav-Kotta \& Paernoja, 2014; Pack et al., 2014; Wibowo \& Yunizal, 1998). ALTIS menggunakan sistem pendingin termoelektrik/thermoelectric coller (TEC) dengan komponen utama elemen peltier yang dialiri oleh sumber arus DC (Astrain, Martinez, \& Rodriquez, 2013; Chen, Liao \& Hung, 2012; Meng, Wang \& Zhang, 2013; Zhang, Mui, \& Tarin, 2010; Zhao \& Tan, 2014). Selain itu, komponen penyusun TEC yang penting adalah heatsink luar. Bagian ini merupakan dudukan untuk meletakkan elemen peltier dan berfungsi dalam mempercepat proses pelepasan kalor pada sisi panas peltier menuju lingkungan (Chu, Chang \& Huang, 2015; Khurshid, Silaipillayarputhur \& Mughanam, 2018; Srikanth \& Ramesh, 2017; Widianto et al., 2014). Heatsink harus mampu melepas kalor dengan cepat pada sisi panas elemen peltier, agar didapatkan performa TEC yang optimal. Oleh karena itu, Heatsink biasanya terbuat dari tembaga dan aluminium, terkait dengan tingginya nilai konduktivitas panas kedua bahan tersebut. Laju perpindahan panas secara konduksi $\left(q_{k}\right)$ melalui bahan berbanding lurus dengan nilai konduktivitas panas bahan, luas permukaan penampang bahan, dan perbedaan suhu antara fluida dengan bahan, serta berbanding terbalik dengan tebal material yang digunakan (Khamkar, et al., 2017). Sementara itu, luas permukaan penampang heatsink adalah hasil dua kali luas dengan panjang sirip (fin) yang dibagi dengan jarak antar sirip (Hamburgen, 1986). Faktor lain yang menentukan kinerja pelepasan panas adalah bentuk dan struktur material heatsink (Yahyaee, Bahman \& Blaapjerg, 2020).

HeatsinkALTIS sebelumnya dirancang oleh Hakim et al. (2016), menggunakan bahan tembaga yang dibuat bersirip dengan ukuran panjang $85 \mathrm{~mm}$, lebar $85 \mathrm{~mm}$, dan tinggi sirip $5 \mathrm{~mm}$. Pembuatan heatsink bersirip dari tembaga cukup sulit dan membutuhkan biaya (bahan dan konstruksi) sebesar Rp. 957.000,00 per unit, atau sebesar Rp. 3.800.000,00 untuk 4 unit heatsink per unit ALTIS. Biaya ini cukup tinggi bagi pedagang ikan keliling.

Hal inilah yang mendasari dilaksanakannya penelitian. Riset bertujuan untuk melakukan modifikasi pada spesifikasi heatsink dan dudukan peltier, agar mendapatkan efisiensi biaya pembuatannya. Modifikasi heatsink dilakukan dengan memadukan bahan tembaga dan sirip alumunium. Tembaga, sebagai bahan plat yang lebih umum tersedia di pasar, dapat dikombinasikan dengan aluminium untuk menurunkan harga bahan dan biaya konstruksi sirip pada heatsink. Desain bahan aluminium yang berbentuk sirip akan dapat meningkatkan luas permukaan dan laju perpindahan panas heatsink, walaupun nilai konduktivitasnya $(205 \mathrm{~W} / \mathrm{m} 2 \mathrm{~K})$ lebih rendah dibandingkan tembaga (385 W/m2K). Sirip alumunium mudah dikonstruksi, murah, serta telah tersedia dalam berbagai model di pasar. Pemilihan dimensi, bentuk, dan ketebalan heatsink disesuaikan dengan dudukan pendingin TEC pada ALTIS. Optimasi ketebalan dudukan peltier mengacu pada ketebalan dudukan pendingin TEC dan dinding tempat penyimpanan ikan. Dudukan peltier dapat dimodifikasi hingga ketebalan $4 \mathrm{~mm}$, sesuai dengan dimensi pendingin TEC. Optimasi ketebalan diperlukan, karena dapat mempengaruhi proses pelepasan panas ke lingkungan. Sebagai contoh, walaupun dudukan peltier yang tipis akan mempercepat proses pemindahan panas, namun hal ini mengakibatkan posisi heatsink luar semakin ke dalam. Oleh karena itu, riset ini meliputi serangkaian pengujian ketebalan untuk mendapatkan performa pendingin TEC yang optimal.

\section{BAHAN DAN METODE}

\section{Bahan}

Bahan yang digunakan adalah satu buah peti penyimpanan ikan ALTIS-2, plat tembaga dengan ketebalan $3 \mathrm{~mm}$, heatsink alumunium bersirip yang memiliki lebar $8 \mathrm{~cm}$ dan ketebalan $1 \mathrm{~cm}$, thermal greace, kipas ukuran $80 \times 80 \times 10 \mathrm{~mm}$ (panjang $\mathrm{x}$ lebar $x$ tinggi), elemen peltier, plat alumunium, serta aksesoris kelistrikan lainya.

\section{Metode}

\section{Pembuatan heatsink luar}

Heatsink dimodifikasi dari spesifikasi dudukan pendingin TEC yang telah dirancang oleh Hakim et al. (2016); Siregar, Zulfia, Wicaksono dan Handoyo (2016); dan Widianto et al. (2014), seperti pada Tabel 1. Dudukan pendingin TEC ini digunakan untuk meletakkan komponen pendingin lainnya, yaitu elemen peltier, dudukan elemen peltier, heatsink, kipas, dan aksesoris lainya.

Bagian bawah heatsink luar dibuat menggunakan bahan plat tembaga yang ditambahkan alumunium bersirip di atasnya. Plat tembaga dibuat persegi berdasarkan kebutuhan spesifikasi dudukan TEC. Plat tembaga dipotong sesuai ukuran, kemudian dihaluskan sampai rata menggunakan amplas. Spesifikasi heatsink dipilih berdasarkan kebutuhan ketebalan. Penambahan jumlah dan pengurangan ketebalan sirip akan menyebabkan peningkatan kalor yang dipindahkan oleh heatsink. Berdasarkan perhitungan, maka bagian atas menggunakan 18 sirip alumunium ( $85 \times 85 \times 10 \mathrm{~mm})$ dengan ketebalan 1 $\mathrm{mm}$. Hal ini didasari oleh ketersedian heatsink alumunium di pasar dan kebutuhan ketebalan maksimal $13 \mathrm{~mm}$. Tembaga dan alumunium kemudian 
Tabel 1. Spesifikasi dudukan sistem pendingin termoelektrik (Thermoelectric Cooler/TEC), dimensi dudukan peltier, dan heatsink alat transportasi ikan segar (ALTIS) dari design (a) Hakim et al. (2016) dan (b) penelitian ini

Table 1. Specification of thermoelectric cooler (TEC) suspending frame, peltier base plate, and heatsink of refrigerated fresh fish container (ALTIS) designed by (a) Hakim et al. (2016) and (b) current research

\begin{tabular}{|c|c|c|c|}
\hline Spesifikasi/Specification & Umum/General & (a) & (b) \\
\hline $\begin{array}{l}\text { Panjang total dudukan TEC/TEC } \\
\text { suspending frame lenght }\end{array}$ & $200 \mathrm{~mm}$ & $200 \mathrm{~mm}$ & $200 \mathrm{~mm}$ \\
\hline $\begin{array}{l}\text { Lebar total dudukan TEC/TEC } \\
\text { suspending frame widht }\end{array}$ & $100 \mathrm{~mm}$ & $100 \mathrm{~mm}$ & $100 \mathrm{~mm}$ \\
\hline $\begin{array}{l}\text { Tebal total dudukan TEC/TEC } \\
\text { suspending frame thick }\end{array}$ & $75 \mathrm{~mm}$ & $75 \mathrm{~mm}$ & $75 \mathrm{~mm}$ \\
\hline $\begin{array}{l}\text { Panjang dudukan peltier/Peltier } \\
\text { base plate lenght }\end{array}$ & $40 \mathrm{~mm}$ & $40 \mathrm{~mm}$ & $40 \mathrm{~mm}$ \\
\hline $\begin{array}{l}\text { Lebar dudukan peltier/Peltier base } \\
\text { plate width }\end{array}$ & $40 \mathrm{~mm}$ & $40 \mathrm{~mm}$ & $40 \mathrm{~mm}$ \\
\hline $\begin{array}{l}\text { Tebal dudukan peltier/Peltier base } \\
\text { plate thick }\end{array}$ & $4-10 \mathrm{~mm}$ & $10 \mathrm{~mm}$ & $(4,5,6,10 \mathrm{~mm})$ \\
\hline Lebar heatsink / Heatsink width & $80-85 \mathrm{~mm}$ & $85 \mathrm{~mm}$ & $85 \mathrm{~mm}$ \\
\hline Panjang heatsink / Heatsink lenght & $80-85 \mathrm{~mm}$ & $85 \mathrm{~mm}$ & $85 \mathrm{~mm}$ \\
\hline Tebal heatsink / Heatsink thick & $\begin{array}{l}\text { Maksimal } 13 \mathrm{~mm} / \\
\text { Maximum } 13 \mathrm{~mm}\end{array}$ & $8 \mathrm{~mm}$ & $13 \mathrm{~mm}$ \\
\hline $\begin{array}{l}\text { Material heatsink / Heatsinks } \\
\text { materials }\end{array}$ & $\begin{array}{l}\text { Metal/ } \\
\text { Metal }\end{array}$ & $\begin{array}{l}\text { Tembaga/ } \\
\text { Copper }\end{array}$ & $\begin{array}{l}\text { Tembaga-alumunium/ } \\
\text { Copper-aluminum }\end{array}$ \\
\hline $\begin{array}{l}\text { Material dudukan peltier/Peltier } \\
\text { base plate materials }\end{array}$ & $\begin{array}{l}\text { Metal/ } \\
\text { Metal }\end{array}$ & $\begin{array}{l}\text { Alumunium/ } \\
\text { Aluminum }\end{array}$ & $\begin{array}{l}\text { Alumunium/ } \\
\text { Alumunium }\end{array}$ \\
\hline
\end{tabular}

dijadikan satu dengan 4 buah baut yang telah ditambahkan thermal greace di antara kedua bidang. Pembanding dalam pengujian adalah heatsink luar ALTIS yang menggunakan bahan tembaga bersirip. Heatsink luar ini memiliki 29 buah sirip, dengan ketebalan $1 \mathrm{~mm}$ dan dimensi $85 \times 85$ × $5 \mathrm{~mm}$ (Gambar 1 ).

\section{Pembuatan dudukan peltier}

Dudukan peltier dibuat dari alumunium dengan tingkat kemurnian sekitar $90 \%$ yang dibentuk persegi dengan sisi $40 \mathrm{~mm}$. Sementara itu, pengujian terhadap dudukan peltier divariasikan dengan ketebalan 4, 5,
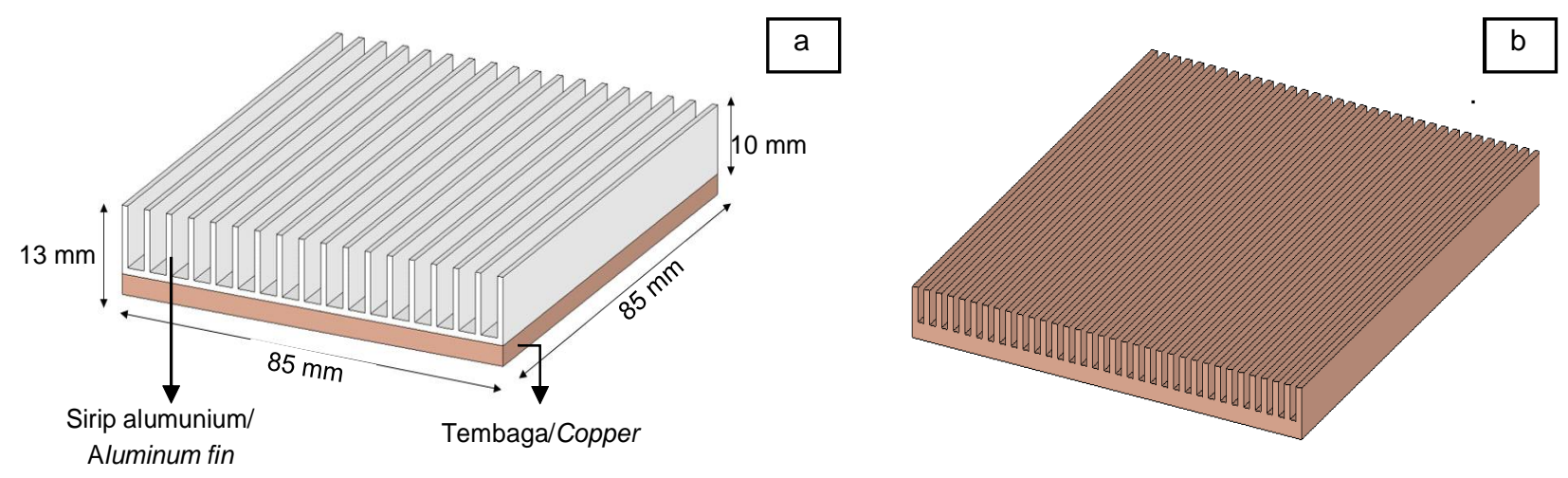

Gambar 1. Rancangan heatsink (a) pada penelitian ini dan (b) Hakim et al. (2016) Figure 1. Design of heatsink from (a) current research and (b) Hakim et al. (2016) 
6, dan $10 \mathrm{~mm}$. Rancangan dudukan peltier dan cara penyusunan komponen pendingin TEC ditunjukkan pada Gambar 2.

\section{Uji performa}

Pengujian dilakukan dengan menyalakan pendingin TEC menggunakan sumber listrik DC KXN 30200 pada tegangan 12 V. Kipas heatsink luar adalah FFB0812EH dengan arus 0,8 A (12V), sedangkan heatsink dalam menggunakan tipe AD0712HS-D91 pada arus 0,2 A (12V). Termometer digital (Lutron TM 496) digunakan untuk mengukur capaian suhu heatsink dalam, heatsink luar, dan ruang penyimpanan ikan. Gambar 2 menunjukkan posisi pengukuran suhu pada pendingin TEC. Pengujian semua parameter dilakukan di dalam ruang yang suhunya dipertahankan konstan $\left(24-26^{\circ} \mathrm{C}\right)$, dengan interval setiap 5 menit selama 95 menit (3 kali ulangan) dan kondisi tanpa beban (tanpa ikan). Suhu awal heatsink dan ruang penyimpanan ikan sama dengan suhu lingkungan pada saat awal pengujian. Heatsink luar dari tembaga murni digunakan sebagai pembanding dalam pengujian. Pengujian ketebalan dudukan peltier juga dilakukan dengan cara dan parameter yang sama.

\section{Pengolahan data}

Analisis statistik dilakukan untuk menguji perbedaan suhu pada variasi ketebalan dudukan peltier. Pengujian beda nyata dilakukan dengan analisis ragam satu arah (one way ANOVA) dan uji lanjut duncan pada perangkat lunak SPSS Ver 16.

\section{HASIL DAN PEMBAHASAN}

\section{Kinerja Heatsink}

Suhu ruang penyimpanan ikan selama pengujian turun dari $25^{\circ} \mathrm{C}$ menjadi $17,8^{\circ} \mathrm{C}$ dalam 95 menit (Gambar 3). Suhu tersebut lebih rendah daripada heatsink desain Hakim et al. (2016), yang sebesar $18,3^{\circ} \mathrm{C}$. Hal ini menunjukkan bahwa modifikasi heatsink luar menggunakan plat tembaga dan sirip alumunium menghasilkan performa TEC yang lebih baik. Sementara itu, data pengukuran menunjukkan pola capaian suhu heatsink dingin yang sama antara kedua perlakuan. Suhu heatsink dingin selama pengukuran turun dan menjadi konstan di sekitar $14^{\circ} \mathrm{C}$. Rata-rata capaian suhu heatsink luar dari
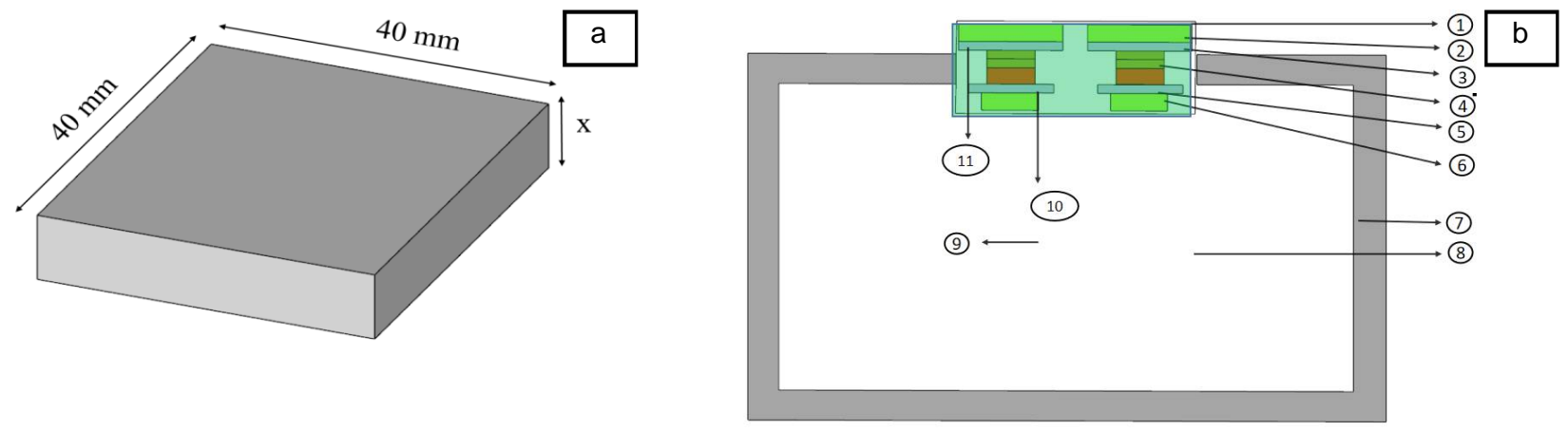

Keterangan/Note :

$\mathrm{x}=4,5,6,10 \mathrm{~mm}$

1. Dudukan TEC/TEC suspending frame

2. Kipas/Fan

3. Heatsink luar/Outer heatsink

4. Peltier

5. Dudukan peltier/Peltier base plate

6. Heatsink dalam/Inner heatsink

7. Dinding peti penyimpanan ikan/Fish container wall

8. Ruang penyimpanan ikan/Fish container room

9. Posisi pengukuran ruang penyimpanan ikan/Fish container measurement point

10. Posisi pengukuran heatsink dalam/Inner heatsink temperature measurement point

11. Posisi pengukuran heatsink luar/Outer heatsink temperature measurement point

Gambar 2. Rancangan dari (a) dudukan peltier dan (b) penyusunan pendingin Termoelectric Cooler/TEC dengan titik pengukuran suhu alat transportasi ikan segar/ALTIS

Figure 2. Design of (a) peltier base plate and (a) termoelectric cooler/TEC arrangement with points of temperature measurement in the refrigerated fresh fish container/ALTIS 

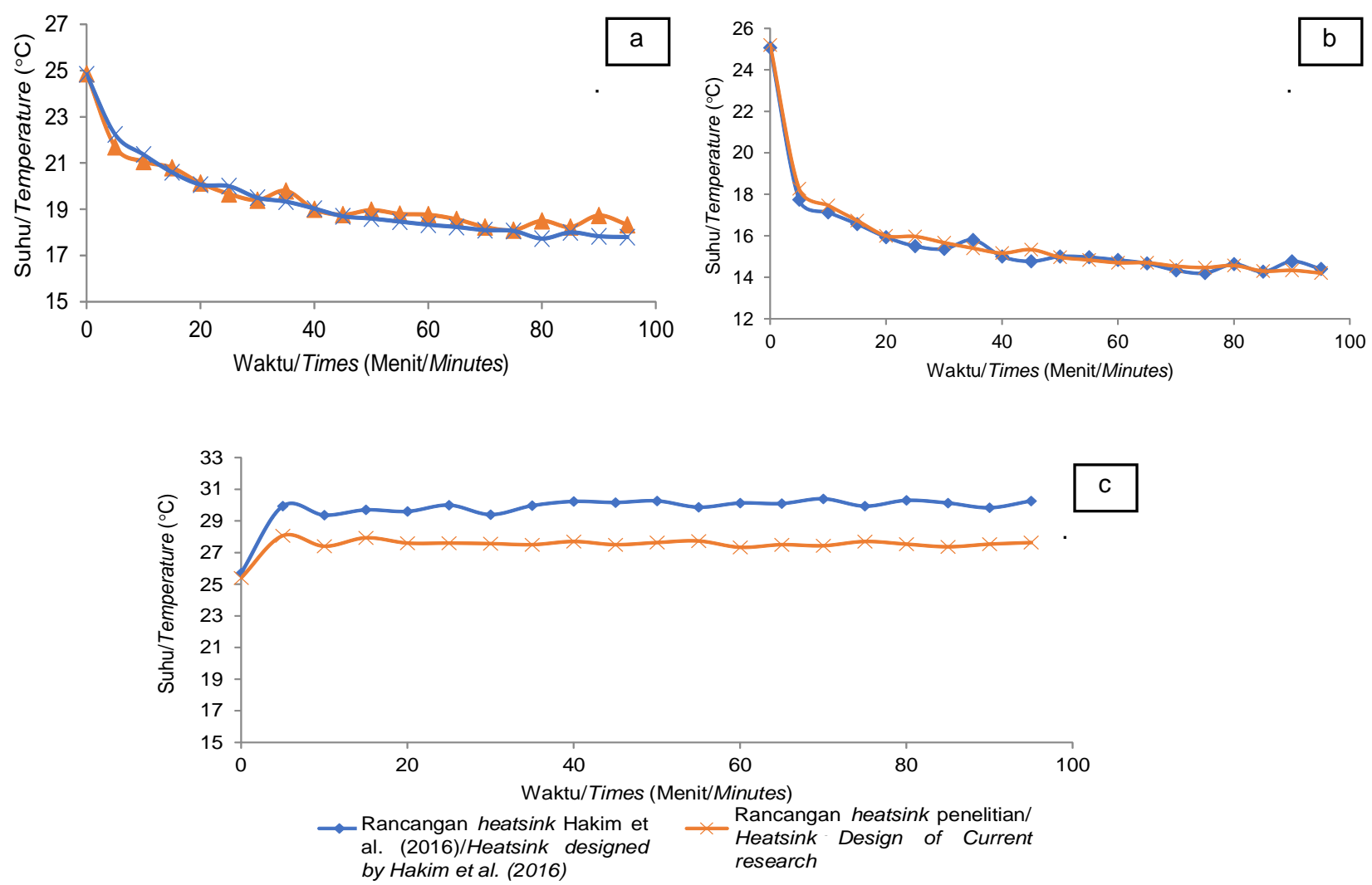

Gambar 3. Suhu dari (a) ruang penyimpanan ikan, (b)heatsink dalam, dan (c) heatsink luar dari rancangan Hakim et al. (2016) dan penelitian ini

Figure 3. Temperature of (a) fish container, (b) inner heatsink, and (c) outer heatsink, from Hakim et al. (2016) and current research design

modifikasi penelitian $\left(27,6^{\circ} \mathrm{C}\right)$ ini lebih rendah dibandingkan heatsink rancangan Hakim et al. (2016), sebesar $30^{\circ} \mathrm{C}$. Hal ini menunjukkan modifikasi juga menyebabkan proses pelepasan panas yang lebih baik. Selain itu, selisih capaian suhu antara ruang penyimpanan ikan dengan heatsink dingin tidak terlalu besar $\left(3^{\circ} \mathrm{C}\right)$.

Efektifitas perpindahan panas melalui heatsink ditentukan nilai resistensi termal heatsink dan dipengaruhi beberapa faktor, yaitu konduktifitas termal bahan, luas penampang heatsink, dan efisiensi sirip (Cengel \& Ghajar, 2015; Holman, 2010; Khamkar et. al., 2017). Penggunaan sirip aluminium dengan luas permukaan lebih besar dapat meningkatkan performa heatsink. Luas kontak permukaan pada rancangan penelitian ini adalah $0,03 \mathrm{~m}^{2}$; sedangkan Hakim et al. (2016) sebesar $0,024 \mathrm{~m}^{2}$. Luas penampang yang lebih besar menyebabkan peningkatan proses pelepasan panas pada heatsink dan sisi panas peltier.

Rancangan pada penelitian ini mempunyai jarak antar sirip aluminium yang lebih renggang dibandingkan Hakim et al. (2016). Hal ini juga dapat mempercepat proses pelepasan panas pada heatsink. Krishnamoorthy dan Jayakumar (2019) menerangkan bahwa perpindahan panas antara bahan tertentu dengan udara terjadi secara konveksi dan ditentukan oleh bentuk geometri permukaan serta model aliran fluida. Peningkatan jarak antar sirip menyebabkan aliran udara yang lebih optimal. Aliran fluida sangat mempengaruhi nilai koefisien perpindahan panas konveksi antara bahan dan fluida (Rahmani et al., 2014). Perpindahan panas secara konveksi terjadi antara heatsink dingin dan udara ruang penyimpanan ikan. Perpindahan secara konveksi ini terjadi akibat adanya perbedaan suhu antara keduanya (Jiji, 2006).

Data kinerja di atas menunjukkan bahwa modifikasi heatsink luar penelitian ini memiliki performa lebih baik, jika dibandingkan dengan rancangan sebelumnya. Selain itu, desain ini mempergunakan bahan dengan ketersediaan yang melimpah, murah, dan proses kontruksi sederhana. Biaya pembuatan heatsink ini adalah Rp. 150.000,00; sementara rancangan Hakim et al. (2016) mencapai Rp. $957.000,00$ per unit. 


\section{Kinerja Variasi Dudukan Peltier}

Hasil pengukuran menunjukkan dudukan peltier dengan ketebalan $10 \mathrm{~mm}$ menghasilkan capaian suhu heatsink dalam yang paling tinggi, sedangkan dudukan 4, 5 dan $6 \mathrm{~mm}$ relatif sama (Gambar 4). Penggunaan tebal braket $5 \mathrm{~mm}$ menghasilkan suhu yang berbeda secara signifikan $(p<0,05)$, jika dibandingkan dengan $10 \mathrm{~mm}$. Sementara itu, penggunaan ketebalan braket $4 \mathrm{~mm}$ dan $5 \mathrm{~mm}$ tidak menghasilkan perbedaan suhu yang signifikan ( $p>0,05)$.

Dudukan alumunium berfungsi untuk memindahkan panas dari heatsink dingin menuju sisi dingin elemen peltier yang selanjutnya dilepas ke lingkungan melalui heatsink luar. Perpindahan panas secara konduksi ini dipengaruhi oleh nilai konduktifitas panas serta ketebalan bahan (Holman, 2010). Semakin tipis bahan dudukan yang digunakan akan menghasilkan perpindahan panas yang makin cepat.
Hal tersebut terlihat dari hasil capaian suhu heatsink dalam pada dudukan peltier dengan ketebalan $4 \mathrm{~mm}$. Penurunan suhu pada 10 menit pertama paling cepat dibanding dengan perlakuan yang lain, sehingga proses perpindahan panas dari heatsink dalam menuju elemen peltier semakin baik. Pola yang sama juga ditunjukkan pada capaian suhu ruang penyimpanan ikan. Perpindahan panas dari ruang penyimpanan ikan menuju heatsink dalam terjadi secara konveksi, akibat perbedaan suhu di antara keduanya.

Faktor lain yang mempengaruhi capaian suhu ruang penyimpanan ikan adalah suhu lingkungan. Perbedaan suhu antara ruang penyimpanan ikan dan lingkungan menyebabkan terjadinya perpindahan panas dari dalam ruang penyimpanan ikan menuju lingkungan melalui dinding. Hasil pengukuran suhu lingkungan pada pengujian dudukan dengan ketebalan $5 \mathrm{~mm}$ memperoleh nilai yang paling rendah dibandingkan suhu lingkungan pengujian yang lain.
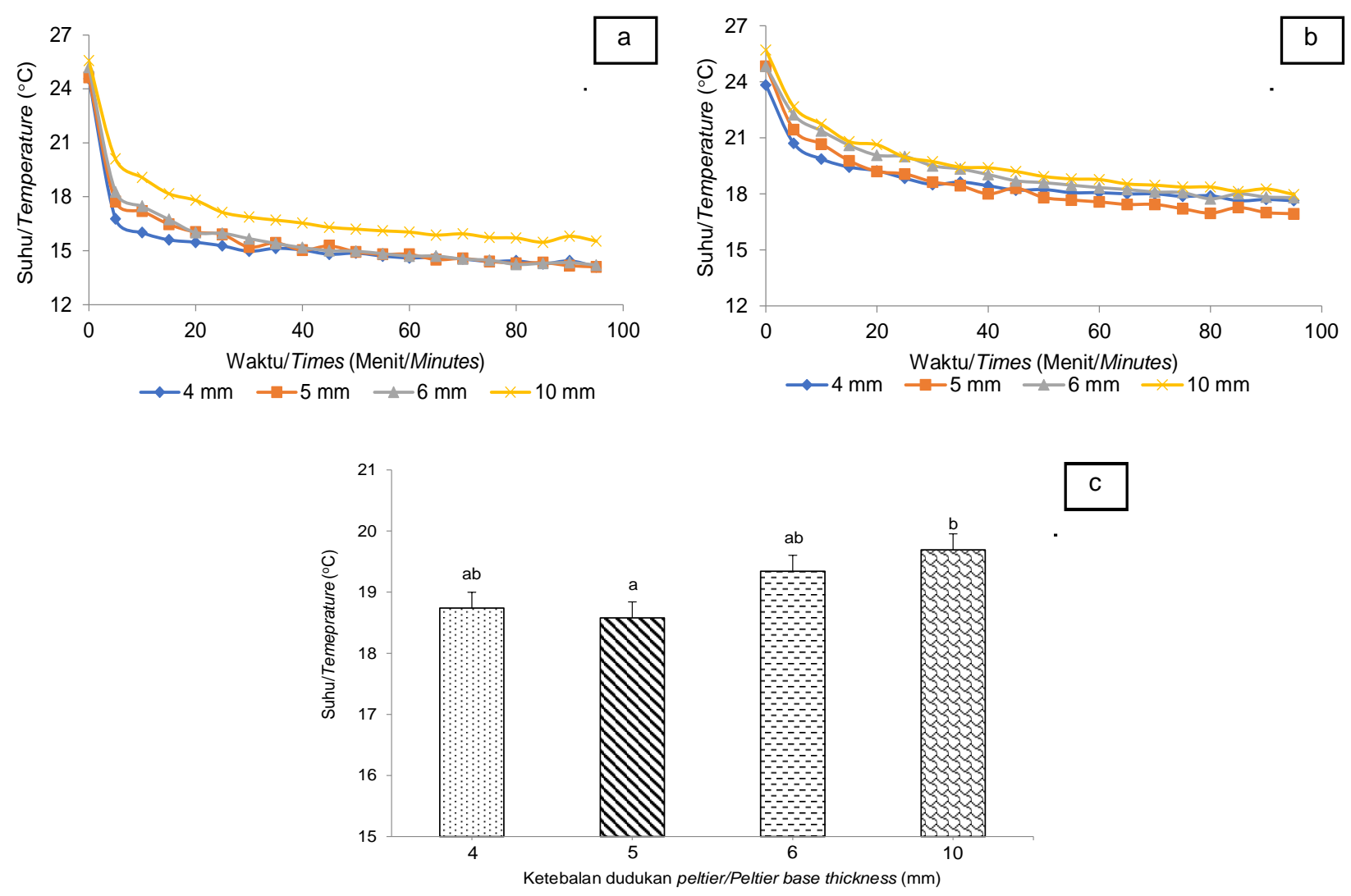

Keterangan/Notes :

Pada grafik (c) menunjukkan tingkat signifikasi $(p<0,05) /$ Notations at $(c)$ express the significance level $(p<0.05)$

Gambar 4. Suhu dari berbagai variasi ketebalan dudukan peltier pada (a) heatsink dalam, (b) ruang penyimpanan ikan, dan (c) hasil akhir ruang penyimpanan ikan

Figure 4. Temperature of various thickness of peltier mounts on (a) inner heatsinks, (b) fish storage rooms, and (c) final fish storage room 
Rata-rata suhu lingkungan dalam pengujian dudukan ketebalan $5 \mathrm{~mm}$ adalah $26,9^{\circ} \mathrm{C}$; sedangkan pada pengujian lainya $27,6^{\circ} \mathrm{C}$. Perbedaan suhu antara lingkungan dan ruang penyimpanan ikan yang relatif kecil menyebabkan suhu ruang penyimpanan ikan pada pengujian dudukan ketebalan $5 \mathrm{~mm}$ paling rendah.

Hasil penelitian ini memperlihatkan bahwa ketebalan dudukan peltier yang terbaik adalah $4 \mathrm{~mm}$, berdasarkan capaian suhu pada heatsink dingin, suhu ruang penyimpanan ikan, kecepatan proses pemindahan panas dari ruang penyimpanan ikan menuju peltier, dan penggunaan bahan yang lebih sedikit. Penggunaan kedua desain komponen pendingin TEC ini dapat dijadikan acuan dalam pembuatan ALTIS-2, sehingga didapatkan penurunan biaya produksi dan peningkatan performanya.

\section{KESIMPULAN}

Desain heatsink luar dengan menggunakan plat tembaga dengan ketebalan $3 \mathrm{~mm}$ dan sirip alumunium dapat mengurangi biaya produksi pembuatan ALTIS2 sekaligus menghasilkan performa pendingin TEC yang optimal. Capaian suhu ruang penyimpanan ikan dengan heatsink ini lebih optimal dan menghemat biaya produksi sebesar Rp. $807.000,00$ per unit. Dudukan elemen peltier dengan bahan aluminium yang memiliki ketebalan $4 \mathrm{~mm}$ juga dapat mempercepat proses perpindahan panas dari ruang penyimpanan ikan menuju peltier.

\section{UCAPAN TERIMA KASIH}

Tulisan ini merupakan kontribusi dari kegiatan riset Penelitian Introduksi Penelitian Aplikasi Teknologi Alat Transportasi Ikan Segar T.A. 2019 di Loka Riset Mekanisasi Pengolahan Hasil Perikanan, Bantul. Penulis mengucapkan terima kasih kepada semua peneliti yang terlibat dalam pelaksanaan kegiatan penelitian.

\section{DAFTAR PUSTAKA}

Astrain, D., Martinez, A., \& Rodriquez, A. (2013). Improvement of a thermoelectric and vapour compression hybrid referigerator. Apllied Thermal Engineering, 39, 140-150. doi: 10.1016/ j.applthermaleng.2012.01.054.

Cengel, Y. A. \& Ghajar, A. J. (2015). Heat And Mass Transfer: Fundamentals \& Applications (Fifth Edition). McGraw-Hill Education, New York.

Chen, W. H., Liao, C. Y., \& Hung, C. I. (2012). A numerical study on the performance of miniature thermoelectric cooler effected by thomson effect. Applied Energy, 89, 464-473.doi: 10.1016/j.apenergy.2011.08.022
Chu, L. M., Chang, W. C. \& Huang, T. H. (2015). A Novel Heat Sink Design and Prototyping for LED Desk Lamps. Mathematical Problems in Engineering, 1-8. doi: $10.1155 / 2015 / 765969$

Gelman, A., Glatman, L., Drabkin, V., \& Harpaz, S. (2001). Effect of storage temperature and preservative treatment on shelf life of the pond-raised freshwater fish, silver perch (Bidyanus bidyanus). Journal Food Protection, 64, 1584-1591.doi: 10.4315/0362-028X64.10 .1584

Hakim, A. R., Siregar, Z., Widianto, T. N., \& Purnomo, A. $\mathrm{H}$. (2016). Analisis peneriaman alat transportasi ikan segar berpendingin menggunakan pendekatan technology appcetance models. Jurnal Pascapanen dan Bioteknologi Kelautan dan Perikanan, 11(1), 1324. doi: 10.15578/jpbkp.v11i1.260

Hamburgen, W. R. (1986). Optimal finned heat sinks (Western Research Laboratory Research Report 86/ 4). Western Research Laboratory. California (US), 16 pHolman, J.P. (2010). Heat Transfer (Tenth Edition). McGraw-Hill, New York.

Holman, J. P. (2010). Heat Transfer (Tenth Edition). McGraw-Hill, New York.

Jiji, L. M. (2006). Heat convection. Spriger, Newyork.

Khurshid, H., Silaipillayarputhur, K. \& Mughanam, T.A. (2018). Design of a Heat Sink for an Electronic Component in ABB Drive using Different Types of Fins. MATEC Web of Conferences 2018. doi: 10.1051/ matecconf/2018249030 ICMMM 2018300909.

Kotta, J., Moeller, T., Orav-Kotta, H., \& Paernoja, M. (2014). Realized niche width of brackish water submerged aquatic vegetation under current enviromental conditions and projected influences of climate change. Marine enviromental research, 102, 88-101. doi: 10.1016/j.marenvres.2014.05.002

Krishnamoorthy, T. \& Jayakumar. (2019). Design and Development of Aluminum-based Heat Sink for Electronic Gadgets. International Journal of Recent Technology and Engineering (IJRTE), 7, 22773878.

Khamkar, N., Waghmode, A., Joshi, A., Supekar, P., Kumar, A., Londhe, K., \& Kaushik, R. V. (2017). Heat Sink Design For Optimal Performance Of Compact Electronic Appliances - a Review. Journal for Advanced Research in Applied Sciences, 4, 13-21.

Meng, J. H., Wang, X. D., \& Zhang, X. X. (2013). Transient modeling and dynamic characteristics of thermoelectric cooler. Applied Energy, 108, 340-348. doi: 10.1016/j.apenergy.2013.03.051.

Pack, E. C., Lee, S. H., Kim, C. H., Lim, C. H., Sung, D. G., Kim, M. H., \& Kim, S. W. (2014). Effects of enviromental temperature change og mercury absopstions in aquatic organism with respect to climate warming. Journal of Toxicology and Enviromental Health-Part A-Current Issues,77(22-24), 1477-1490. doi: 10.1080/15287394.2014.955892

Rahmani, M. A., Fdhila, R. B., Gronqvist, A., Tysell, M., Persson, T. L., Benendo, M. \& Uvgard, Z. (2014). Thermal management and design optimization of heatsink for cooling performance improvement during 
transient heat. The 6th International Conference on Applied Energy Generation. Energy Procedia, 61, 1665 - 1668. doi: 10.1016/j.egypro.2014.12.187

Siregar, Z.A., Zulfia, N., Wicaksono, C.B. \& Handoyo, W.T. (2016). Laporan Teknis Rancang Bangun Pengembangan Alat Transportasi Ikan Segar ALTIS-2 Type E100. Loka Riset Mekanisasi Pengolahan Hasil Perikanan.

Srikanth, V. \& Ramesh, C. G. (2017). Thermal Design of Heat Sink and Optimization of Fin Parameters. International Journal of Innovative Research in Science, Engineering and Technology, 6, 107-115

Wibowo, S. \& Yunizal. (1998). Penanganan Ikan Segar. Badan Litbang Pertanian. Jakarta.

Widianto, T. N., Hermawan, W., \& Utomo, B. S. B. (2014). Uji coba peti ikan segar berpendingin untuk pedagang ikan keliling. Jurnal Pascapanen dan Bioteknologi Kelautan dan Perikanan, 9(2), 185191.doi: 10.15578/jpbkp.v9i2.111

Yahyaee, A., Bahman, A. S. \& Blaabjerg, F. (2020). A Modifification of Offset Strip Fin Heatsink with HighPerformance Cooling for IGBT Modules. Appied. Science, 10, 1112. doi: 10.3390/app1003 1112.

Zhang, H. Y., Mui, Y. C., \& Tarin, M. (2010). Analysis of thermoelectric cooler performance for high power electronic pagkages. Applied Thermal Engineering. 30, 561-568. doi: 10.1016/j.applthermaleng. 2009.10.020.

Zhao, D., \& Tan, G. (2014). A review of thermoelectric cooling: Materials, modeling and applications. Applied Thermal Engineering. doi: 10.1016/ j.applthermaleng.2014.01.074. 